\title{
AVALIAÇÃO MICROBIOLÓGICA E FÍSICO-QUÍMICA DE LINGUIÇA TOSCANA NO MUNICÍPIO DE MOSSORÓ, RN
}

\section{M.V.P. Bezerra, M.R. Abrantes, M.K.S. Silvestre, E.S. Sousa, M.O.C. Rocha, J.G. Faustino, J.B.A. Silva}

Universidade Federal Rural do semi-Árido, Departamento de Ciência Animal, Laboratório de Inspeção de Produtos de Origem Animal, km 47, BR 110, CEP 59625-900, Mossoró, RN, Brasil. E-mail: jeanberg@ufersa. edu.br

\section{RESUMO}

Com o objetivo de avaliar a qualidade microbiológica e físico-química da linguiça toscana comercializada no Município de Mossoró, RN, foram analisadas 28 amostras de seis supermercados, verificando-se o Número Mais Provável (NMP) de coliformes termotolerantes, Salmonella spp. e bactérias psicrotróficas, umidade, $\mathrm{pH}$ e atividade de água. Todas as amostras estavam dentro do padrão vigente que estabelece um limite máximo de $5 \times 10^{3} \mathrm{NMP} / \mathrm{g}^{-1}$ para coliformes termotolerantes conforme a ANVISA. Na contagem de bactérias psicrotróficas houve uma variação de 2,9 x $10^{1}$ a $1,31 \times 10^{4} \mathrm{UFC} / \mathrm{g}^{-1}$. Das 28 amostras pesquisadas quanto a presença de Salmonella spp., em cinco verificou-se a presença deste micro-organismo em $25 \mathrm{~g}$. Para umidade, todas as amostras encontravam-se dentro da legislação estabelecida $(<70 \%)$ e para atividade de água os limites variaram de 0,772 a 0,809. Os valores de pH das amostras estavam entre 5,7 e 6,2. Apesar das amostras analisadas estarem dentro do estabelecido pela legislação brasileira, faz necessária a aplicação de boas práticas, visto que a contaminação por micro-organismos psicrotróficos e Salmonella foi significativa, podendo diminuir a vida de prateleira do produto e causar danos a saúde pública.

PALAVRAS-CHAVE: Coliformes termotolerantes, Salmonella spp., psicrotróficas, análises físicoquímicas.

\begin{abstract}
MICROBIOLOGICAL AND PHYSICO-CHEMICAL EVALUATION OF TOSCANA SAUSAGE IN THE CITY OF MOSSORÓ, STATE OF RIO GRANDE DO NORTE, BRAZIL. Aiming to evaluate the microbiological and physico-chemical quality of the toscana sausage commercialized in the city of Mossoró, state of Rio Grande do Norte, Brazil, samples from 6 supermarkets were analyzed, verifying the most likely number (MLN) of thermotolerant coliforms, Salmonella spp., and psychrotrophic bacteria, humidity, $\mathrm{pH}$ and water activity. All the samples were within the current standards which establish a maximum limit of $5 \times 10^{3} \mathrm{MLN} / \mathrm{g}$ for thermotolerant coliforms according to ANVISA. On the psychrotrophic bacteria count there was a variation of 1.46 to 4.10 expressed in $\log _{10}$ values. Of the 28 samples analyzed for the presence of Salmonella spp., in 5 the presence of this microorganism was verified in $25 \mathrm{~g}$. In regard to humidity, all the samples were found to be in accordance with the established legislation (lower than $70 \%$ humidity), and for water activity the limits varied between 0.772 and 0.809 . The $\mathrm{pH}$ values were within normalcy, ranging from 5.7 to 6.2. In spite of the fact that the analyzed samples are in accordance with Brazilian laws, it is necessary to apply good practices, since the contamination by psychrotrophic microorganisms and Salmonella was significant and could harm the public health and reduce the product's shelf life.
\end{abstract}

KEYWORDS: Thermotolerant coliforms, Salmonella spp., psychrotrophic bacteria, physico-chemical analysis.

No mercado nacional existe uma grande variedade de derivados de carne suína, entre os produtos processados, a linguiça frescal do tipo toscana (constituída exclusivamente de carne suína) representa alternativa para o aproveitamento de cortes suínos menos nobres devido ao baixo custo de produção e grande aceitação pelo mercado consumidor (RAMUNDO et al., 2005).
A linguiça tipo frescal, por seu próprio mecanismo de produção, comercialização e composição química, possui alto risco de contaminação por agentes microbianos, devendo ser acondicionada em ambientes higiênicos e sob refrigeração (RODRIGUES et al., 2000).

As prováveis fontes de contaminação para esses produtos compreendem as carnes, os envoltórios, os temperos ou condimentos, bem como a água utilizada 
em todas as operações de limpeza e manutenção, manipulação de máquinas e utensílio (Oliveira et al., 1992).

ForsYTHE (2002) afirmou que a maioria dos alimentos contém nutrientes suficientes para sustentar o crescimento microbiano e muitos fatores podem propiciar, prevenir ou limitar o crescimento de micro-organismos. Entre estes fatores intrínsecos e extrínsecos os mais importantes são: a atividade de água $(\mathrm{Aa}), \mathrm{pH}$ e temperatura.

A presença de bactérias nos alimentos, além de favorecer a deterioração e/ou redução da vida útil desses produtos, possibilita a veiculação de patógenos, acarretando potenciais riscos à saúde do consumidor. Assim, a higiene correta dos alimentos é necessária para garantir a segurança e a sua salubridade em todos os estágios de sua elaboração até o produto final, minimizando a preocupação para a saúde pública (CORTEZ, 2003).

Desta forma objetivou-se avaliar a qualidade microbiológica e físico-química de linguiças toscanas comercializadas no Município de Mossoró, RN.

Foram analisadas semanalmente amostras de linguiça toscana comercializadas a granel em seis supermercados de Mossoró, RN, sendo que em cinco foram realizados cinco repetições e em um supermercado três, devido à falta do produto nos dias de coleta, totalizando assim 28 amostras, todas com selo deinspeçãofederal (SIF). As amostras adquiridas (500 g) eram acondicionadas pelos próprios balconistas em embalagens plásticas e transportadas em caixas isotérmicas e transportadas ao Laboratório de Inspeção de Produtos de Origem Animal (LIPOA) da UniversidadeFederal Rural doSemiárido(UFERSA), onde eram submetidas logo em seguida as análises microbiológicas e físico-químicas.

Foram pesados assepticamente $25 \mathrm{~g}$ decada amostra ehomogeneizados em $225 \mathrm{~mL}$ deágua peptonada $0,1 \%$ em stomacher. Diluições decimais sucessivas foram realizadas em $90 \mathrm{~mL}$ deágua peptonada $0,1 \%$. A diluição obtida correspondeu à diluição $10^{-1}$, a partir da qual foram obtidas as demais diluições decimais ate $10^{-4}$. Em seguida, foram submetidas às técnicas recomendadas para verificação de NMP de coliformes termotolerantes, Salmonella spp. e bactérias psicrotróficas. As análises microbiológicas seguiram as recomendações da Instrução Normativa No 62 do Ministério da Agricultura, Pecuária e Abastecimento (BRASIL, 2003).

As análises físico-químicas foram realizadas em triplicatas no intuito de diminuir erro deamostragem. A determinação da umidade foi realizada segundo as especificações dos Métodos Analíticos Oficiais para Controle de Produtos de Origem Animal eSeus Ingredientes (BRASIL, 1981).

A atividade da água (Aa) foi determinada utilizando-se o equipamento automático Testo 650 Water Activity System, sendo realizadas as análises de acordo com a recomendação do fabricante. $\mathrm{O}$ pH foi determinado utilizando $\mathrm{pHmetro}$ PHTEKPHS-3B com a introdução de uma sonda específica na massa.

Os resultados das análises de coliformes termotolerantes, psicrotróficas e Salmonella obtidas das amostras de linguiça toscana analisadas estão expressos em logarítmo e apresentados na Tabela 1.

Levando-se em consideração a enumeração de coliformes termotolerantes, das 28 amostras de linguiça toscana analisadas, todas encontravam-se conforme o padrão vigente que estabelece um limite máximo de $5 \times 10^{3} \mathrm{NMP} / \mathrm{g}$ ou seu $\log 10$ igual a 3,699, para coliformes termotolerantes (AGÊNCIA..., 2001).

De acordo com FrANCO (2002), os coliformes termotolerantes servem como indicadores higiênicosanitários na obtenção, nas fases tecnológicas, no processamento e/ou na comercialização de produtos cárneos e pode acarretar riscos à saúde dos consumidores.

Na contagem de bactérias psicrotróficas houve uma variação de $2,9 \times 10^{1}$ a $1,31 \times 10^{4} \mathrm{UFC} / \mathrm{g}$ ou 1,46 a 4,11 conforme a Tabela 1 expressos em valores de $\log 10$. Os micro-organismos psicrotróficos, embora não previstos na legislação vigente, foram utilizados como indicadores de vida de prateleira neste experimento.

Para Miyagusku et al. (2003), as bactérias psicrotróficas estão entre os micro-organismos que apresentaram bom desenvolvimento em temperaturas de refrigeração, capaz de deteriorar o produto, diminuindo a vida útil de alimentos refrigerados.

Tabela 1 - Média das contagens de coliformes termotolerantes, bactérias psicrotróficas e presença de Salmonella de amostras de linguiça toscana de seis supermercados no Município de Mossoró, RN, 2010.

\begin{tabular}{cccc}
\hline Supermercados & Coliformes termotolerantes & Bactérias psicrotróficas & Salmonella \\
\hline A & 1,25 & 2,46 & Presente \\
B & 1,30 & 4,10 & Ausente \\
C & 1,70 & 3,20 & Presente \\
D & 1,78 & 3,83 & Presente \\
E & 1,23 & 4,11 & Presente \\
F & 1,37 & 1,46 & Presente \\
\hline
\end{tabular}


Das 28 amostras pesquisadas quanto à presença de Salmonella sp., em cinco $(17,85 \%)$ verificou-se a presença deste micro-organismo em $25 \mathrm{~g}$. Dos seis supermercados analisados, quatro (A, C, D e E) apresentaram pelo menos uma amostra positiva para presença de Salmonella spp. em pelo menos uma repetição.

Resultados semelhantes a este estudo quanto à pesquisa de Salmonella spp. foram encontrados por Tessmann et al. (2001) que, ao analisarem 25 amostras de linguiça de carne suína, detectaram a presença de Salmonella spp. em cinco amostras.

Mürmann et al. (2005) demonstraram que baixas contagens de Salmonella spp. podem estar presentes em linguiça frescal de carne suína. Desta forma, o risco que esse produto oferece ao consumidor estará relacionado à existência de condições que permitam a multiplicação da bactéria no alimento.

As amostras de linguiça em estudo apresentavam registro de Inspeção Federal que devem ser fiscalizadas por órgãos oficiais, obedecer aos requisitos mínimos de elaboração dos produtos e ter suas instalações inspecionadas por fiscais do Ministério da Agricultura, Pecuária e Abastecimento (MAPA). Assim sendo, devem apresentar condições apropriadas de consumo, entretanto, com a manipulação a que são submetidas nos estabelecimentos de venda, estão propícias à contaminação por uma possível falta de aplicação das boas práticas.

O desenvolvimento de micro-organismos é favorecido por características intrínsecas da carne, particularmente sua composição química, elevada disponibilidade de água (Aa) e $\mathrm{pH}$ próximo a neutralidade (CONTRERAS et al., 2002).

A média das análises físico-químicas está representada na Tabela 2. As amostras das linguiças toscanas analisadas obtiveram valores de umidade abaixo de $70 \%$, em relação à atividade de água e pH os resultados variaram de 0,772 a 0,809 e de 5,7 a 6,2, respectivamente.

Pode-se observar que todas as amostras apresentaram valores de umidade em conformidade com a legislação vigente, que determina limite máximo de $70 \%$ (BRASIL, 2000).

$\mathrm{O}$ teor de água de um alimento constitui-se em um dos mais importantes e mais avaliadosíndices em alimentos, devido à grande importância econômica por refletir o teor de sólidos de um produto e sua perecibilidade. Umidade fora das recomendações técnicas resulta em grandes perdas na estabilidade química, na deterioração microbiológica, nas alterações fisiológicas (brotação) e na qualidade geral dos alimentos (VINCENZI, 2009).

Oresultado médio de 0,782 para atividade deágua encontrado neste estudo está em desacordo com a pesquisa de PAULINo (2005), que verificou atividade deágua de linguiça toscana em diferentes dias, sendo no primeiro dia de análise média de 0,93 . A atividade de água de um alimento é a medida mais acurada para se determinar a possibilidade do crescimento microbiano (MBUGUA; KARURI, 1994), pois influencia na estabilidade microbiana e, para muitos alimentos este crescimento é prevenido com valor entre 0,6-0,7 (BelL; LABUZA, 1992).

Os valores considerados como normais de $\mathrm{pH}$ para produtos cárneos oscilam entre 5,4 e 6,2 (MANTOVANI et al., 2011), sendo assim, os valores de pH das linguiças toscana em estudo encontraram-se dentro da normalidade.

Segundo Almeida (2005), o valor do pH da carne tem grande importância, uma vez que influencia na microbiota do produto, ajuda a classificar seu estado de conservação, além de ser um importante fator para determinação da cor. Milani et al. (2003) sugeriram que quanto mais elevado o $\mathrm{pH}$, maior é a probabilidade proliferação microbiana.

Portanto, as linguiças toscanas comercializadas em estabelecimentos comerciais de Mossoró, RN, apresentaram contagem de coliformes dentro dos padrões. As contagens elevadas de bactérias psicrotróficas observadas podem reduzir a vida de prateleira do produto.

Os padrões físico-químicos apresentaram-se dentro da normalidade indicando uma boa qualidade do produto.

Tabela 2 - Média e Desvio Padrão do teor de umidade, atividade de água (Aa) e pH de linguiças toscanas comercializadas no Município de Mossoró, RN, 2010.

\begin{tabular}{cccc}
\hline Supermercados & Umidade & Aa & $p H$ \\
\hline A & $52,79 \% \pm 6,95$ & $0,809 \pm 0,03$ & $6,0 \pm 0,12$ \\
B & $49,44 \% \pm 7,61$ & $0,775 \pm 0,06$ & $6,2 \pm 0,19$ \\
C & $49,32 \% \pm 6,28$ & $0,774 \pm 0,03$ & $6,2 \pm 0,36$ \\
D & $50,53 \% \pm 5,57$ & $0,779 \pm 0,03$ & $6,1 \pm 0,13$ \\
E & $51,97 \% \pm 6,45$ & $0,772 \pm 0,02$ & $5,8 \pm 0,61$ \\
F & $47,01 \% \pm 0,38$ & $0,773 \pm 0,02$ & $5,7 \pm 0,63$ \\
\hline Total & $49,96 \% \pm 5,91$ & $0,782 \pm 0,03$ & $6,0 \pm 0,38$ \\
\hline
\end{tabular}




\section{REFERÊNCIAS}

AGÊNCIA NACIONAL DE VIGILÂNCIA SANITÁRIA. (Brasil). Resolução da Diretoria Colegiada da Agência Nacional de Vigilância Sanitária, Regulamento Técnico sobre os Padrões Microbiológicos para Alimentos. RDC $\mathrm{N}^{\circ} 12$, de 2 de janeiro de 2001. Diário Oficial da República Federativa do Brasil, Poder Executivo, Brasília, DF, 2001.

ALMEIDA, O.C. Avaliação físico-química e microbiológica de lingüiça toscana porcionada e armazenada em diferentes embalagens, sob condições de estocagem similares às praticadas em supermercados. 2005. Dissertação (Mestrado em Tecnologia de Alimentos) - Faculdade de Engenharia de Alimentos da Universidade Estadual de Campinas, São Paulo, 2005.

BELL, L.N.; LABUZA, T.P. Composition influence on the $\mathrm{pH}$ of reduced-moisture solutions. Journal Food Science, v.57, p.732-734, 1992.

BRASIL. Ministério da Agricultura, Pecuária e Abastecimento. Instrução Normativa $\mathrm{n}^{\circ} 4$ de 31 de março de 2000. Regulamento Técnico de Identidade e Qualidade de lingüiça. Diário Oficial da República Federativa do Brasil. Poder Executivo, Brasília, 5 de abril de 2000.

BRASIL. Ministério da Agricultura, Pecuária e Abasteci,emto. Instrução Normativa n. 62 de 26 de agosto de 2003. Métodos analíticos oficiais para análises microbiológicas para controle de produtos de origem animal e água. Diário Oficial da República Federativa do Brasil, Brasília, 18 set. 2003.

CONTRERAS, C.J.; BROMBERG, R.; CIPOLLI, K.M.V.A.B.; MIYAGUSKU, L. Higiene e sanitização na indústria de carnes e derivados. São Paulo: Varela, 2002. 181p.

CORTEZ, A.L.L. Indicadores de qualidade higiênico-sanitária em linguiça frescal comercializada no Município de Jaboticabal-SP. 2003. 42f. Dissertação (Mestrado em Medicina Veterinária Preventiva) - Faculdade de Ciências Agrárias e Veterinárias, Universidade Estadual Paulista, Jaboticabal, 2003.

FORSYTHE, S.J. Microbiologia da segurança alimentar. Porto Alegre: Artmed, 2002. 424p.

FRANCO, R.M. Escherichia coli: ocorrência em suinos abatidos na Grande Rio e sua viabilidade experimental em Lingüiça Frescal Tipo Toscana. Tese. (Doutorado na Área de Concentração em Higiene Veterinária e Processamento Tecnológico de Produtos de Origem Animal) - Universidade Federal Fluminense, Niteroi, RJ, 2002.

MANTOVANI, D.; CORAZZA, M.L.; CARDOZO FILHO, L.; COSTA, S.C. Avaliação higiênico-sanitária de linguiças tipo frescal após inspeção sanitária realizada por órgãos federal, estadual e municipal na região noroeste do Paraná. Revista Saúde e Pesquisa, v.4, n.3, p.357-362, 2011.

MBUGUA, S. K.; KARURI, E. G. Preservation of beef using bacteriostatic chemicals and solar drying. Food and Nutrition Bulletin, v.15, n.3, p.262-268, 1994.

MILANI, L.I.G.; FRIES, L.L.M; PAZ, P.B.; BELLÉ,M.; TERRA, N.N. Bioproteção de lingüiça de frango. Ciência e Tecnologia de Alimentos, v.23, n.2, p.161-166, 2003.

MIYAGUSKU, L.; CHEN, F.; LEITÃO, M.F.F.; BAFFA, O. Avaliação microbiológica e sensorial da vida-útil de cortes de peito de frangos irradiados. Ciência e Tecnologia de Alimentos, v.23, p. 7-16, 2003.

MÜRMANN, L.; SANTOS M.C.; CARDOSO M. Prevalence and level of Salmonella enterica in pork fresh sausages purchased in southern Brazil. In: of 135 INTERNATIONAL SYMPOSIUM SALMONELLA AND SALMONELLOSIS,13., 2005, Saint-Malo, França. Proceedings. Saint-Malo, 2005. p.443-444.

OLIVEIRA, L.A.T.; FRANCO, R.M.; CARVALHO, J.C.A.P. Enterobacteriaceae em especiarias utilizadas na elaboração de embutidos cárneos. Higiene Alimentar, v.6, n.22, p.27-33, 1992.

PAULINO, F. de O. Efeito da redução de gordura e substituição parcial de sal em lingüiça suina tipo toscana. Dissertação (Mestrado em Higiene Veterinária e Processamento Tecnológico de Produtos de Origem Animal) - Universidade Federal Fluminense, Niterói, RJ, 2005.

RAMUNDO, A.; COUTO, S.M.; LANZILLOTTI, H.S. Elaboração e análise sensorial de lingüiças caseiras. Higiene Alimentar, v.19, n.128, p.70-77, 2005.

RODRIGUES, R.A.; TERRA, N.N.; FRIES, L.L.N. Lactato de sódio, um conservante natural no processamento de lingüiça frescal. Higiene Alimentar, v.14, n.75, p.56-21, 2000.

TESSMANN, C.; LIMA, A.S.; DUVAL, E.H.; MACEDO, M.R.P.; SILVA, W.P. Prevalência de Salmonella sp. e Staphylococcus aureus em linguiças do tipo frescal derivadas de carne suína. In: CONGRESSO BRASILEIRO DE MICROBIOLOGIA, 21., 2001, Foz do Iguaçu. Anais. Foz do Iguaçu, 2001. p.390.

VINCENZI, R. Apostila de análise de alimentos da (UNIJUI, RS) Química Industrial de Alimentos, 2009. Disponivel em: <http://pt.scribd.com/doc/7164422/ Apostila-de-AnAlise-de-Alimentos>. Acesso em: 27 abr. 2012.

Recebido em 10/2/11

Aceito em 5/5/2012 